4. Намаканов Б.А. Девиантное поведение подростков - проблема школьного воспитания // Наука и школа. - 2011. - № 1. - С. 112-117.

5. Плахина Е.А. К вопросу об информационной безопасности в сети Интернет // Известия ТулГУ. Технические науки. - 2020. - Вып. 12. - С. 342-345.

6. Семенько Т.В. Безопасность в сети Интернет // Интерактивная наука. - 2016. - № 6. - С. $42-44$.

7. Славутский Л.А., Славутская Е.В. Простые нейросетевые алгоритмы как основа навыков работы с искусственным интеллектом // Информационные технологии в электротехнике и электроэнергетике. Материалы XII Всероссийской научно-технической конференции (Чебоксары). - 2020. - C. 457-460.

Барнаш A.B., Амбарян A.C.

\title{
Взаимодействие детей старшего дошкольного возраста в образовательной деятельности дошкольной образовательной организации
}

\author{
Филиал ГБОУ ВО «СГПИ» в г. Ессентуки \\ (Россия, Ессентуки)
}

doi: 10.18411/lj-06-2021-155

\section{Аннотация}

Тема взаимодействия детей старшего дошкольного возраста в образовательной деятельности интересна и актуальна в современном образовательном пространстве необходимостью формирования у старших дошкольников готовности к совместной деятельности со сверстниками и недостаточностью научных данных, позволяющих грамотно осуществить этот процесс, особенно в дошкольных образовательных организациях комбинированного типа.

Ключевые слова: старший дошкольный возраст, образовательная среда, совместная деятельность, взаимодействие.

\section{Abstract}

The topic of interaction between senior preschool children in educational activities is interesting and relevant in the modern educational space by the need to form older preschoolers' readiness for joint activities with peers and the lack of scientific data that allow to competently carry out this process, especially in preschool educational organizations of a combined type.

Keywords: senior preschool age, educational environment, joint activities, interaction.

В Федеральном государственном образовательном стандарте дошкольного образования одной из задач является формирование готовности к совместной деятельности со сверстниками, развитие творческих способностей и потенциала каждого ребенка как субъекта взаимоотношений с самим собой, другими детьми, взрослыми и миром [1]. Современная педагогика активно выстраивает свою новую личностно-ориентированную парадигму. В основе современного образовательного процесса лежит личность ребенка с присущей ему неповторимостью характера и поведения. Проблема воспитания - это не только вопрос о средствах и методах воспитания, но и вопрос о ценностях, нормах и моральных правилах, которые человек воспринимает и которым следует при общении с людьми [3].

В то же время в системе дошкольного образования появляются негативные тенденции: чрезмерная ориентация на интеллектуальное развитие ребенка, технологизация современной жизни, что приводит к недоразвитию эмоциональной и коммуникативной сфер, а, следовательно, к формированию неадекватного отношения к сверстникам. Поэтому одной из главных задач в старшем дошкольном возрасте должно стать формирование готовности к совместной деятельности со сверстниками. Приоритет общечеловеческих ценностей, гуманистический принцип, лежащий в основе современного образовательного процесса, требует развития такого типа межличностных отношений, как совместное действие, сотворчество, партнерство, 
навыки командной работы, способствующие формированию личности, свободно проявляющей себя в социальной и духовной сферах.

Педагогическая наука, признавая личность главной ценностью общества, отводит ей роль активного творческого субъекта познания, общения, действия и взаимодействия. Коллективная деятельность как одна из ценностей культуры составляет основу жизненно важных способов поведения и действий человека, придает характеристики его самореализации, а также позволяет передавать опыт позитивного, конструктивного взаимодействия.

Можно выделить следующие направления формирования готовности к совместным действиям:

- коммуникативные, то есть обогащающие у детей формы и способы овладения речью и другими видами общения, посредством которых устанавливаются межличностные взаимодействия партнеров в процессе сотрудничества в совместной деятельности;

- эмоциональная ценность - создание эмоционально положительной мотивационной основы для дошкольников старшего возраста для сотрудничества со своими сверстниками в классе;

- познавательные, формирующие представление о сверстнике как возможном партнере в совместной деятельности, о принципах и моделях совместной деятельности и т.д.;

- эффективные (поведенческие), обеспечивающие практическое развитие и использование у детей навыков совместных действий, сосредоточиться на выборе модели сотрудничества в зависимости от задач и содержания совместной деятельности.

Цель нашей исследовательской работы - развитие способности дошкольников самостоятельно отбирать модель совместной деятельности для совместного решения образовательной задачи. В исследовании участвовали дети старшего дошкольного возраста - 24 человека (12 человек - экспериментальная группа, 12 человек контрольная группа) муниципального бюджетного учреждения - дошкольная образовательная организация «Детский сад № 18 комбинированного вида ст. Суворовской.

Осуществлялась диагностика в рамках индивидуальной беседы с детьми и использованием методики «Лабиринты» Е.Е. Кравцовой. Результаты нашей исследовательской работы в экспериментальной и контрольной группах мы отобразили на рисунке 1.

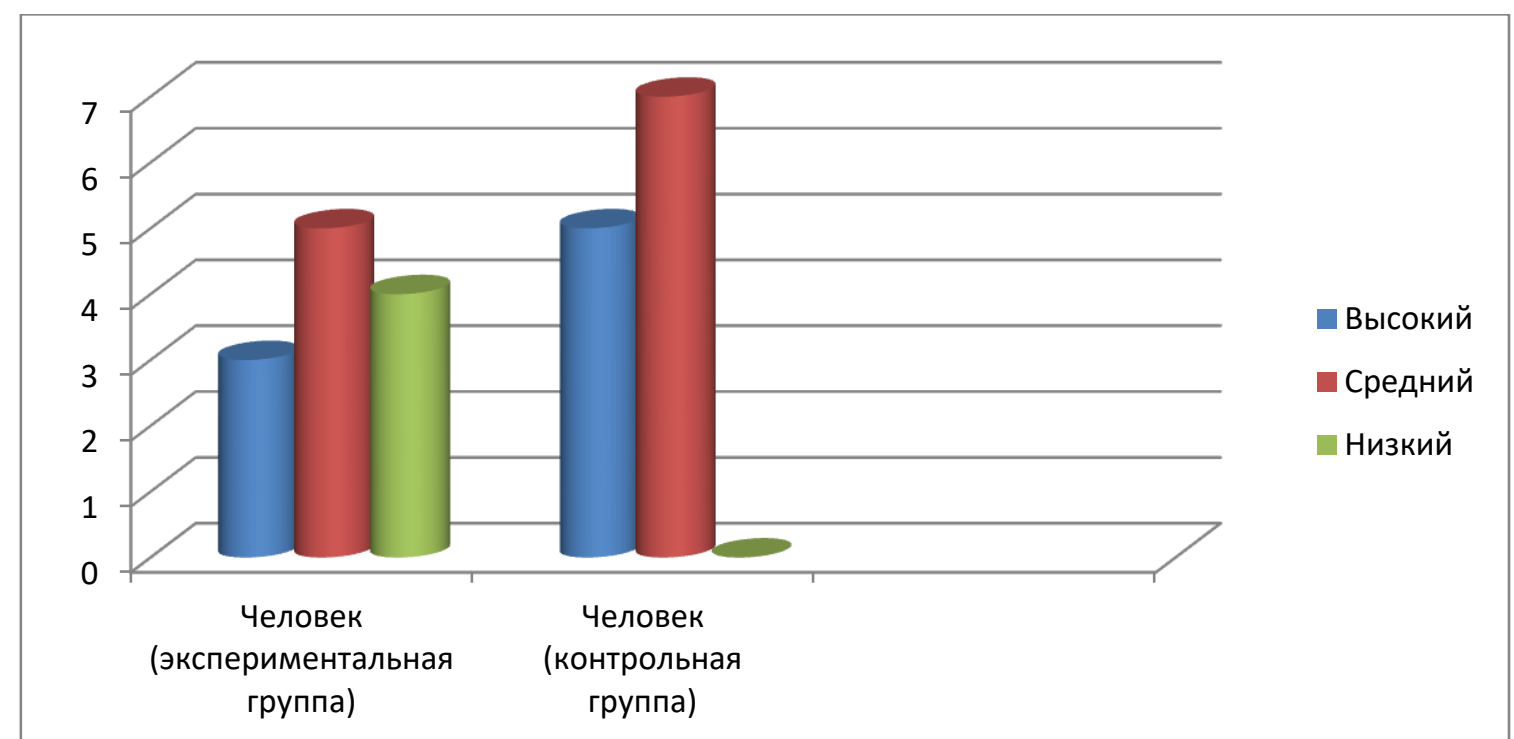

Рисунок 1 - Динамика уровней сформированности представлений воспитанников о понятии совместная деятельность со сверстниками в экспериментальной и контрольной группах. 
Из полученных данных, представленных на рисунке 1, видно, что все дети перешли на средний и высокий уровень формирования идей для совместной деятельности со сверстниками, низкий уровень исчез. В группе стало преобладать некое позитивное согласованное взаимодействие в совместной деятельности, стало более осознанным отношение к совместной взаимодействию. Среди дошкольников возрос интерес к сверстникам, нет детей, предпочитающих учиться самостоятельно. Произошли значительные изменения в восприятии дошкольниками того, как действовать сообща.

Таким образом, наше исследование показало, что формирование готовности к совместной деятельности со сверстниками у старших дошкольников происходит успешно при реализации поэтапной педагогической работы, что обеспечивает последовательное усвоение детьми все более сложных моделей совместных действий. Переход от менее сложной модели к более сложной рассматривался детьми как естественная потребность научиться новому способу совместного решения проблемы, который является актуальным и интересным для них.

$$
* * *
$$

1. Федеральный Государственный образовательный стандарт дошкольного образования [Текст]: утвержден приказом Министерства образования и науки Российской Федерации от 17 октября 2013г., №1155 / Министерство образования и науки Российской Федерации. - Москва: 2013г.

2. Бардышевская, М. К. Диагностика психического развития ребенка: учебное пособие для вузов/М. К. Бардышевская. - 2-е изд., испр. и доп. - Москва: Издательство Юрайт, 2021. - 153 с. - (Высшее образование). - ISBN 978-5-534-10411-0. - URL: https://urait.ru/bcode/472487

3. Курочкина, И. Н. Методика обучения и воспитания в области дошкольного образования. Этикет: учебное пособие для вузов/И. Н. Курочкина. - 2-е изд., испр. и доп. - Москва: Издательство Юрайт, 2021. - 134 с. - (Высшее образование). - ISBN 978-5-534-08486-3. - URL: https://urait.ru/bcode/470664

4. Смирнова, Е. О. Общение и его развитие в дошкольном возрасте: учебное пособие для вузов / Е. О. Смирнова. - 2-е изд., перераб. и доп. - Москва: Издательство Юрайт, 2021. - 163 с. - (Высшее образование). - ISBN 978-5-534-12814-7. - URL: https://urait.ru/bcode/476766

5. Хохрякова, Ю. М. Педагогика раннего возраста: учебник для вузов/Ю. М. Хохрякова. - 2-е изд., испр. и доп. - Москва: Издательство Юрайт, 2021. - 262 с. - (Высшее образование). - ISBN 978-5534-08630-0. - URL: https://urait.ru/bcode/472092

\section{Вакуленко О.Б., Москоленко Е.В., Гордеева Н.В. \\ Основные направления реализации программы этнокультурного казачьего образования в Амурской области \\ ГАУ ДПО «Амурский областной институт развития образования»} (Россия, Благовещенск)

doi: $10.18411 / \mathrm{j}-06-2021-156$

\section{Аннотация}

Основная задача реализации программы этнокультурного казачьего образования на территории Амурской области заключаются в развитии концепции регионального образования и создании единого образовательного и воспитательного пространства с учетом культурно-этнической региональной специфики.

Ключевые слова: Приамурье, амурское казачество, программа этнокультурного казачьего образования.

\section{Abstract}

The main task of implementing the program of ethnocultural Cossack education on the territory of the Amur Region is to develop the concept of regional education and create a single educational environment, taking into account the cultural and ethnic regional specifics.

Keywords: Priamurye, Amur Cossacks, program of ethnocultural Cossack education. 